\title{
Financial Risk Management: when does Independence fail?
}

\author{
By Augustin Landier, David SRaer and David Thesmar *
}

The recent turmoil on credit markets has drawn attention to the risk management function. On many trading floors around the world, traders have been writing insurance against rare events: examples include keeping long positions on CDO tranches or selling protection against default (CDS). In normal times, it is the role of risk management to ensure that the received insurance premia are not entirely considered as income, and that enough capital is set aside to protect the institution against the risk that it is taking. In the period that led to the current crisis, however, risk management has failed to play this role. ${ }^{1}$ This is particularly troubling as the finance industry is one that has embraced the notion of using counter-powers to limit risk and the importance of "dissent" within organizations. For instance, the Head of Risk Management at KfW, a German bank, argued for the superiority of having a "central" risk management function, independent of the business units: "The great advantage [of central risk management] is the absence of conflict of interest. The central risk management is not driven by the market. We look at the business from a different angle; we are not involved at the personal level." (quoted by PriceWaterHouseCoopers, 2007).

The purpose of this paper is to study when such virtuous organizational design may fail. We first propose a model of risk management. Following Augustin Landier et al (forthcoming), we model the trading floor as a simple hierarchy. The role of the trader (T) is to select an asset to invest in, while the risk manager (RM) can decide to approve, or not. Due to his

* Landier: NYU-Stern, alandier@stern.nyu.edu. Sraer: UC-Berkeley, sraer@berkeley.edu. Thesmar: HEC Paris and Centre for Economic Policy Research, thesmar@hec.fr. We thank Wouter Dessein for insightful comments.

${ }^{1}$ For instance, the Swiss bank UBS has identified risk management malfunctions as one important source of its multibillion dollar subprime related loss. "UBS's analysis identified a number of factors within the Risk Control functions, specifically within Market Risk, that suggest that the overall Risk Control framework was insufficiently robust" (UBS Shareholder Report on Writedowns) compensation structure and limited liability, $\mathrm{T}$ has an intrinsic preference for the riskiest asset, even though such a selection can be value destroying. In this context, giving a different compensation structure to the RM may elicit an optimal behavior from the trader: because she knows RM has no particular interest in letting the risky asset go through, T will more often feel compelled to make the efficient choice. Thus, our model has a level of RM independence that alleviates the trader's bias towards risk taking.

We then use this model to look at risk management failures. First, we find that in our model an increase in the convexity of trader compensation diminishes the likelihood that risk-management successfully induces traders to pick the right asset. This allows us to make sense of the claim that, in recent years, the pressure that was put on traders to increase their PNL may have prevented risk management from performing its function. Second, we find that an increase in the risk of assets traded reduces the favorable impact of risk management independence. The intuition is similar to the first result: because $\mathrm{T}$ values the upside potential of assets, she becomes more "biased" towards risky assets, and more insensitive to RM's potential reluctance to approve. Third, in an extension of the model, we find that risk-budgets contingent on information help implementing the efficient asset choice but become ineffective if that information is noisier. Fourth, we investigate the potential for side-payments to reduce the effectiveness of independence. Such side payments occur when the trader can implement a transfer to the risk manager, for instance through career opportunities in the front office. ${ }^{2} \mathrm{Un}$ der certain assumptions, we find that an increase in $\mathrm{T}$ compensation favors collusion on the Trading floor and makes risk management ineffective.

Our paper deviates from the finance literature on risk management by shifting the focus of the analy-

\footnotetext{
${ }^{2}$ For instance, Jérôme Kerviel, the rogue trader whose directional bets on index futures led to a loss of $5 \mathrm{bn} €$ at SocGen, a French bank, was a former back office employee.
} 
sis from methods of risk evaluation (see for instance Anthony Saunders and Marcia Cornett, 2006), towards organization design. We do not simply emphasize the "dissenting" function of risk-management (a la Landier et al, 2009) but show under what circunstances it is more likely to break-down. We believe this is an important contribution as recent risk management failures seem to have been driven as much by organizational issues as by the inherent difficulty to measure credit risk. For instance, citing the UBS shareholder report on subprime-related write-downs, René Stulz (2008) argues that communication of risk exposure to the top management was highly inefficient.

In tackling the issue of risk management independence, our paper borrows from the literature on heterogeneity in organizations. Most of the existing literature has the feature that delegation is a "necessary evil", since the resulting divergence in preferences between the principal and the agent distorts incentives (as for instance in Guillermo Calvo and Stanislaw Wellisz, 1979, or Philippe Aghion and Jean Tirole, 1997, or more recently Wouter Dessein, 2002 and Eric Van Den Steen, 2007). More recently, some papers have investigated the virtues of heterogeneity in organizations. Yeon-Koo Che and Navin Kartik (2008) look at a the problem of a Decision Maker who needs advice. They find that it is always efficient to hire an adviser with different priors, since it provides him with incentives to search for information.

This paper has four remaining Sections. Section 2 presents the basic set-up. Section 3 characterizes the equilibria in this simple set-up and derives comparative statics. Sections 4 and 5 discuss extensions of the basic model.

\section{The Basic Model}

\section{A. Set-Up}

The organization is an asset management firm whose goal is to select an asset. It consists of two agents: a Risk manager (he, RM) and a Trader (she, T). There are two states $S$ of Nature labeled 1 or 2 , both occuring with probability $1 / 2$. The Trader selects one of two assets labeled 1 or 2 . The Riskmanager approves, or not, the purchase of the asset. The RM bases his decision on his information on the cost of capital $\tilde{c}$, which has c.d.f. $F$, assumed to be twice differentiable and weakly concave.

Asset payoffs $\widetilde{r}_{i}(i=1,2)$ are the following. When the state of nature is $i$, asset $i$ pays off $R_{i}$. When the state of nature is $j \neq i$, then asset $i$ fails: it pays off $-L_{i}$. We assume that both assets have identical exante present values (i.e. $R_{1}-L_{1}=R_{2}-L_{2}$ ) and that asset 1 is riskier $\left(R_{1}>R_{2}\right)$.

We turn to payoffs for T and RM. When no asset is selected, both $\mathrm{T}$ and $\mathrm{RM}$ receive zero utility flow. When asset $i$ is selected, T receives utility $g\left(\widetilde{r}_{i}\right) . g$ is the indirect utility of the Trader and captures the combination of attitude toward risk and compensation contracts. $\mathrm{T}$ is limitedly liable for the loss on her portfolio $g\left(-L_{i}\right)=0$. Quite intuitively, we assume $g^{\prime}>0$ : hence, $g\left(R_{1}\right)>g\left(R_{2}\right)$. T thus has an intrinsic preference for the riskier asset.

When asset $i$ is selected and approved, the RM receives indirect utility $h\left(\widetilde{r}_{i}\right)-\widetilde{c}$. First, the RM's utility is decreasing in the cost of capital: this assumption is meant to capture the fact that it is the role of risk managers to allocate the Value at Risk across different traders. Thus, accepting T's asset prevents the Risk-Manager from accepting other investments. Implictly, we therefore assume that the RM wants to maximize the number of investments realized by the business units under his supervision, or that he is supposed to internalize the opportunity cost of accepting high cost of capital assets. Secondly, the Risk manager's indirect utility $h$ is a function of the asset's final payoff. If $\tilde{r}_{i}<0$, we assume limited liability such that $h\left(\widetilde{r}_{i}\right)=0$. If the asset's payoff is positive, $h\left(R_{i}\right)>0$. Thus, the risk manager is partly sensitive to the success. We do not, however, need to assume that $h\left(R_{1}\right)>h\left(R_{2}\right)$.

Furthermore, in order to simplify the exposition, we assume that the Trader is "more risk seeking" than the Risk-manager in the following sense:

$$
\frac{g\left(R_{1}\right)}{g\left(R_{2}\right)}>\frac{F\left(h\left(R_{2}\right) / 2\right)}{F\left(h\left(R_{1}\right) / 2\right)}
$$

which means that Trader's utility is steep enough in the upside potential of assets.

\section{B. Timing}

The sequence of actions has four different steps. At date 1 , there is a publicly available signal $\sigma$ on the state of nature. The signal precision is $\alpha=P(\sigma=$ $i \mid S=i)>1 / 2$. At date 2 , the Trader chooses the asset (1 or 2). In period 3, the Risk-manager learns the cost of capital $\widetilde{c}$. He approves investment, or not. In period 4, final payoffs are realized. 


\section{Equilibrium Definition}

The strategy space is the following. When T picks asset $j$, she reacts to the signal $\sigma$, as well as her expectation of the RM's approval decision $\rho^{e}$. In turn, the RM's approval decision $\rho$ depends on the signal $\sigma$, the cost of capital $\tilde{c}$, and the asset $j$ selected by T. We look for the (unique) subgame perfect Nash equilibrium of this game.

\section{Baseline Model}

We first characterize two types of equilibria. Reactive equilibria are equilibria where the Trader always selects the "best" asset, i.e. the asset that fits the signal (asset 1 with signal 1, asset 2 in case of signal 2). Non reactive equilibria are equilibria where the Trader always selects asset 1 , i.e. the asset for which she has an intrinsic bias.

PROPOSITION 1: Equilibrium characterization 1. Assume that:

$$
\begin{aligned}
& \alpha \cdot F\left(\alpha h\left(R_{2}\right)\right) \cdot g\left(R_{2}\right)> \\
& (1-\alpha) \cdot F\left((1-\alpha) h\left(R_{1}\right)\right) \cdot g\left(R_{1}\right)
\end{aligned}
$$

In this case, the equilibrium is reactive, i.e. the Trader always selects the asset that fits the signal.

2. If condition (2) is not met, then the equilibrium is non reactive, i.e. the Trader always selects asset 1.

The above proposition demonstrates that the equilibrium is either reactive or non reactive. Condition (2) ensures that $T$, after observing signal 2, indeed prefers to select asset 2 over asset $1 .^{3}$ The left hand side of this condition is the expected utility of a Trader selecting asset 2: the RM will approve it with probability $F\left(\alpha h\left(R_{2}\right)\right)$, upon approval, the asset will have a positive payoff with probability $\alpha$, and in this case, the Trader will receive $g\left(R_{2}\right)$. The right hand side is the expected utility of a Trader that selects asset 1 , even if the signal is 2 . In this case, the RM will approve with probability $F\left((1-\alpha) h\left(R_{1}\right)\right)$, the probability of

\footnotetext{
${ }^{3}$ The condition ensuring that $\mathrm{T}$ selects asset 1 when the signal is 1 is given by:

$$
\begin{aligned}
& \alpha \cdot F\left(\alpha h\left(R_{1}\right)\right) \cdot g\left(R_{1}\right)> \\
& (1-\alpha) F\left((1-\alpha) h\left(R_{2}\right)\right) \cdot g\left(R_{2}\right)
\end{aligned}
$$
}

which, given that $\alpha>1 / 2$ and condition (1), always holds. positive payoff is only $1-\alpha$, and T can expect compensation $g\left(R_{1}\right)$. Overall, one simple consequence of condition (2) is that, when the signal is more informative ( $\alpha$ larger), risk management is better at eliciting reactivity. This comes from the fact that both RM and $\mathrm{T}$ prefer the asset that has a positive payoff, even though the Trader has a bias towards asset 1 .

The above proposition leads to a few interesting comparative static properties which we summarize in the following proposition.

PROPOSITION 2: The scope for the reactive equilibrium diminishes when:

1. The trader's compensation becomes more sensitive to high payoffs,

2. The risk-manager's compensation becomes more sensitive to high payoffs,

3. The payoffs of the risky asset are hit by a meanpreserving spread.

First, if the Trader's compensation becomes more sensitive to the upside potential of assets, the scope for reactive equilibria diminishes. This can be seen by increasing $g\left(R_{1}\right) / g\left(R_{2}\right)$ in condition $(2)^{4}$. Basically, when the bias of the trader becomes too strong, it overwhelms the resistance of risk-management. The witnesses of the failure of risk-management within large banks often mention the overwhelming power of incentives at the front-office as the source of the back-office inability to "pull the break". For example, according to a senior executive in a troubled bank, "Senior managers got addicted to the revenues and arrogant about the risks they were running. As long as you could grow revenues, you could keep your bonus growing" (Eric Dash and Julie Creswell, 2008). Second, if the Risk Manager's compensation becomes more sensitive to the upside of the asset, reactivity is also impaired. This amounts to increasing $h\left(R_{1}\right)$ while holding $h\left(R_{2}\right)$ constant in condition (2). This particular comparative static exercise allows to rationalize the need for risk manager's independence: to act as an efficient counterpower, risk managers cannot enjoy much of the upside generated by the investment he is supposed to supervise.

Third, an increase in the risk of asset 1 reduces, in general, the scope for reactivity. To see this, assume the RM's compensation is flat: $h\left(R_{1}\right)=h\left(R_{2}\right)=w$. This maximizes RM independence under the (natural) constraint that $h^{\prime}>0$. In this case, a mean-preserving

\footnotetext{
${ }^{4} \mathrm{An}$ increase in the trader's optimism about the risky project outcome would have that effect too.
} 
spread of asset 1 is equivalent to increasing $R_{1}$ while holding $R_{1}-L_{1}$ constant. This makes condition (2) less likely to hold and reactivity harder to sustain. Thus, our baseline model suggests that an increase in the risk borne by a particular class of assets, may make risk management ineffective, even though its compensation makes it relatively independent.

\section{Information-dependent Cost of Capital}

In this Section, we amend the baseline model by allowing the cost of capital to depend on the signal. An organization might choose to make the cost of capital higher (lower) for projects about which negative (positive) information is received. As we show, this should, in theory, be the case, but in practice some banks have had trouble implementing it. To make computations simple and transparent, we assume that, conditional on signal $i$, the cost of capital of asset $i$ is $\widetilde{c}$, while the cost of capital of asset $j \neq i$ is $\widetilde{c}+\lambda$. Hence, the cost of capital of the asset that is not in line with the signal is larger: this reflects the fact that the riskiness of the unfit asset is higher, and hence, should command a higher cost of capital.

The rest of the model is identical to the baseline model. In this context, it is easy to show that the reactivity condition (2) becomes:

$$
\begin{aligned}
& \alpha \cdot F\left(\alpha h\left(R_{2}\right)\right) \cdot g\left(R_{2}\right)> \\
& (1-\alpha) \cdot F\left((1-\alpha) h\left(R_{1}\right)-\lambda\right) \cdot g\left(R_{1}\right)
\end{aligned}
$$

Assume the signal is 2. If the Trader selects asset 2, the risk manager will approve if and only if $\alpha h\left(R_{2}\right)>$ $\widetilde{c}$, as in the baseline model. But in the new model, if $\mathrm{T}$ selects asset 1 , the Risk Manager approves if and only if $\widetilde{c}<(1-\alpha) h\left(R_{1}\right)-\lambda$. Hence, the fact that the cost of capital is correlated with the signal reinforces the RM's incentives to reject the wrong asset selection.

Thus, an increase in $\lambda$ relaxes the new condition (3) and makes reactivity easier to sustain.

PROPOSITION 3: For all parameters, there exists $a \lambda$ above which the reactive equilibrium is implemented.

All in all, the model suggests that it is always possible to insure reactivity by making the cost of capital borne by the risk-manager contingent on information received about projects. Anecdotal evidence suggests banks did not all use such mechanism. For instance, UBS (2008) reveals that "the full benefit of UBS's ability to obtain funding at a relatively low cost in the market was passed through to the business, without any adjustment to reflect the nature of the relevant business activity". In practice, implementing a statecontingent cost-of-capital can be done by using the risk premia implicit in observed asset prices. However, this mechanism looses its grip when (1) information if weak (low $\alpha$ ) or (2) the cost of capital is contingent on market-prices that reflect abnormally low risk-premia (low $\lambda$ ). For example, if the cost of leveraging positions becomes abnormally small compared to the underlying risks, the cost of capital will become ineffective at implementing reactivity. In our model, this effect is even amplified when assets are riskier or trader compensation contracts more convex in performance.

\section{Collusion on the Trading Floor}

This last Section looks at collusion between $\mathrm{T}$ and RM. To do this, we assume that side payments between $\mathrm{T}$ and $\mathrm{RM}$ are feasible: for instance, traders can offer potentially lucrative career opportunities to risk managers in exchange for lax supervision.

We focus on the case where condition (2) is satisfied: in the absence of side payments, reactivity would prevail. Furthermore, to simplify exposition, we only consider the case when the signal is 2 . At this stage, we reduce T's choices to the following alternative: either she selects asset 2, or she selects asset 1 and gives the bribe $w$ to the RM conditional on approval. In this case, the expected utility from selecting asset 1 and bribing the RM is given by:

$$
\max _{w} F\left((1-\alpha) h\left(R_{1}\right)+w\right) \cdot\left[(1-\alpha) \cdot g\left(R_{1}\right)-w\right]
$$

while the expected utility from selecting asset 2 and not bribing the RM is simply $\alpha . F\left(\alpha h\left(R_{2}\right)\right) \cdot g\left(R_{2}\right)$. Then, it is straightforward to show the following proposition:

PROPOSITION 4: Assume $F(x)=x$ and $g\left(R_{1}\right)>$ $h\left(R_{1}\right)$ Then, there exists a set of parameters such that:

1. the equilibrium without side-payments is reactive

2. the equilibrium with side-payment is non reactive

Moreover, this set of parameters expands as $g\left(R_{1}\right)-h\left(R_{1}\right)$ increases. 
Thus, collusion may make independent risk management less effective, in a fashion similar to Jean Tirole (1986). As it turns out, the internal inquiry following the $\$ 7.7$ billion fraudulent trading loss at Société Générale in January 2008 mentions “internal collusion involving a Middle Office operational agent dedicated to JK's [Jérôme Kerviel, the rogue trader] activity" (Société Générale, 2008). The other result of proposition 4 is that, as the difference in upsides between $\mathrm{T}$ and RM increase, side-payments are more and more likely (in the sense of an increase in the parameter space) to reduce reactivity. Indeed, when $T$ has much to gain with the risky asset, she can afford to compensate the RM for not blocking the investment.

\section{REFERENCES}

Aghion, Philippe, and Jean Tirole. 1997. "Formal and Real Authority in Organizations." The Journal of Political Economy, 105:1-29.

Calvo, Guillermo, and Stanislaw Wellisz. 1979. "Hierarchy, Ability, and Income Distribution,” The Journal of Political Economy, 87: 991-1010.

Che, Yeon-Koo and Navin Kartik. 2008. "Opinions as Incentives.” Working Paper Columbia University. Dash, Eric, and Julie Creswell. 2008. "Citigroup saw no Red Flags Even as it Made Bolder Bets.” The New York Times. November 23, A1

Dessein, Wouter. 2002. "Authority and Communication in Organizations." The Review of Economic Studies, 69: 811-838.

Landier, Augustin, David Sraer, and David Thesmar. Forthcoming. "Optimal Dissent in Organizations." The Review of Economic Studies

PriceWaterhouseCoopers. 2007. "Creating Value: Effective Risk Management in Financial Services.”

Saunders, Anthony, and Marcia M. Cornett. 2005. Financial Institutions Management: A Risk Management Approach. Irwin/McGraw-Hill

Société Générale, 2008, "Mission Green Summary Report"

Stulz, René. 2008. "Risk Management Failures: What Are They and When Do They Happen?", Fisher College of Business Working Papers Series

Tirole, Jean. 1986. "Hierarchies and Bureaucracies: on the Role of Collusion in Organizations", Journal of Law, Economics and Organizations, 2: 181-214

Van Den Steen, Eric. 2007. "The Cost of Incentives under Disagreement (Can Employees Be Too Motivated?)." Working Paper MIT.

UBS. 2008. "UBS Shareholder Report on Write Downs." 